\title{
Minimum operating pressure for a gas storage salt cavern under an emergency: a case study of Jintan, China
}

\author{
Tongtao Wang ${ }^{1, *}$, Guoyin $\mathrm{An}^{2}$, Shuai $\mathrm{Xu}^{2}$, Jianchao Jia ${ }^{2}$, Wenquan Wang ${ }^{2}$, and Jaak J.K. Daemen ${ }^{3}$ \\ ${ }^{1}$ State Key Laboratory of Geomechanics and Geotechnical Engineering, Institute of Rock and Soil Mechanics, Chinese \\ Academy of Sciences, Wuhan, 430071 Hubei, PR China \\ 2 Jiangsu Gas Storage Company, PetroChina, Zhenjiang, 212004 Jiangsu, PR China \\ ${ }^{3}$ Mackay School of Earth Sciences and Engineering, University of Nevada, Reno, 89557 NV, USA
}

Received: 15 July 2020 / Accepted: 30 September 2020

\begin{abstract}
Decreasing the gas pressure is one of the most effective methods to increase the working gas capacity of salt cavern Underground Gas Storages (UGS). In this paper, KING-1 and -2 caverns of Jintan salt cavern UGS, Jiangsu province, China, are studied as an example to investigate their responses under extremely low gas pressure. A 3D geomechanical model of the two caverns is built based on the geological features and rock properties of the host rock salt formation. Different operating conditions are simulated. Safety evaluation criteria for completion casing and caverns are proposed. Thresholds of the indicators consisting of the criteria are given to find the potential minimum gas pressure and the safe working duration of the two caverns. Calculation results indicate that axial strain (along the vertical direction) can perfectly reflect the effects of low gas pressure on the safety of completion casing. The indicators calculated based on the stresses have advantages compared to those based on deformation in assessing the safety of the salt cavern under such low gas pressure and short operating time conditions. The minimum gas pressure gradient of KING-1 and -2 caverns at the casing shoe can decrease from about $7 \mathrm{kPa} / \mathrm{m}$ to $5 \mathrm{kPa} / \mathrm{m}$, viz., the minimum gas pressure can decrease from $7 \mathrm{MPa}$ to $5 \mathrm{MPa}$. The maximum duration for $5 \mathrm{MPa}$ is no more than 118 days. Taking KING-1 cavern as an example, the working gas volume can increase about $17.3 \%$. Research results can provide references for Jintan salt cavern UGS coping with gas shortages.
\end{abstract}

\section{Introduction}

Rock salt has good plastic deformation, low permeability, self-healing and is soluble (Bayram and Bektasoglu, 2020; Chen et al., 2020; Wang et al., 2019). It is regarded as the most ideal host for geologic energy (gas, oil and compressed air) storage. Salt caverns have been widely constructed for gas storage. Due to its rapid injection and delivery capacity (Bayram and Bektasoglu, 2020; Wang et al., 2018b), salt cavern gas storage is usually used for the continuous gas supply under emergency, such as extreme weather, trunk pipeline accident, and facility maintenance. The capacity of the gas storage salt cavern is mainly determined by its volume, and maximum and minimum gas pressure (Ozarslan, 2012; Wang et al., 2019). Low minimum gas pressure means low volume of cushion gas and large amount of working gas under emergency. The gas storage cavern usually is located in the rock salt formation at a depth ranging from several hundred meters to more than $1 \mathrm{~km}$ and its volume reaches hundreds and even

\footnotetext{
* Corresponding author: ttwang@whrsm.ac.cn
}

thousands of thousand cubic meters. If the minimum gas pressure is too low, the deviatoric stress will exceed the strength of the rock mass. Cavern collapse and casing damage may then take place (Bérest and Brouard, 2003). Therefore, how to determine the minimum allowable pressure is the base and precondition for evaluating the capacity of a gas storage salt cavern under emergency.

Jintan salt cavern Underground Gas Storage (UGS) is one of the most important infrastructures to ensure the gas supply security of the West-East Gas Pipeline. It has a storage capacity of about $1.0 \times 10^{9} \mathrm{~m}^{3}$ and a working gas capacity of about $0.7 \times 10^{9} \mathrm{~m}^{3}$. The original design maximum and minimum gas pressures are 17 and $7 \mathrm{MPa}$ respectively (Wang et al., 2017). Actually, the true gas pressures for any given cavern may be slightly different from the initial design values for the depth and shape of different caverns differ. If the minimum gas pressure of Jintan UGS can be decreased without causing detrimental effects to the cavern safety, more working gas can be delivered. This would be valuable for reducing any gas shortage. For example, if the minimum gas pressure of all caverns of Jintan can decrease by $1 \mathrm{MPa}$, we can roughly calculate 
that the working gas will increase by more than $4.0 \times 10^{7} \mathrm{~m}^{3}$. However, two adverse effects may affect a salt cavern UGS when the gas pressure is too low. (i) The completion casing may suffer tensile damage, and this may cause a tightness failure of the cavern. When a salt cavern is operated with a low gas pressure, the stress difference in the rock mass around the cavern will increase greatly. Especially, some stresses in the cavern roof will increase notably if the cavern roof has a poor strength structure (e.g., a large-span flat roof). This may cause tensile damage of the completion casing, and possibly even leakage of the entire salt cavern. (ii) Cavern instability may take place. Due to the gas pressure being decreased while the far field stress remains constant, the stress difference to which the rock mass around the cavern is subjected increases notably. This may cause local or global instability. The pillar between adjacent caverns is the weakest part (Wang et al., 2015b), and has a high possibility of failing. Therefore, study on the safety of the salt cavern UGS operated with different extreme low gas pressures is prerequisite for increasing the UGS working gas by decreasing the minimum gas pressure.

The minimum gas pressure determination for a salt cavern used for energy storage (such as natural gas, hydrogen, or compressed air) is always difficult. Many scholars studied this problem. Adams (1997) evaluated the maximum and minimum gas pressure of a salt cavern UGS in Prairie Evaporite mining district, Saskatchewan, Canada, and indicated that the minimum gas pressure gradient at the casing shoe should be no less than $4.5 \mathrm{kPa} / \mathrm{m}$ during the initial three cycles of gas injection-production. After that it could be decreased to $3.4 \mathrm{kPa} / \mathrm{m}$. DeVries and Nieland (1999) used the damage potential method and a multi-mechanism deformation coupled with a fracture model to simulate the damage and self-healing after damage of rock salt, and tried to determine the minimum operating gas pressure for a salt cavern UGS. Crotogino and Huebner (2008) evaluated the development of using salt caverns for hydrogen storage in Germany, and proposed that the minimum operating gas pressure could be $1 / 3$ of the maximum operating pressure. Stone et al. (2009) investigated the feasibility of using salt caverns for large scale hydrogen storage in the UK, and pointed out that the cushion gas could be decreased by about $10 \sim 15 \%$ when the minimum operating pressure decreases 1 MPa. Wang et al. (2010) studied the effects of cavern depth, roof span, thickness of salt left above the cavern roof, and thickness of interlayer above cavern roof on the minimum gas pressure of a salt cavern UGS, and indicated that the cavern roof span was the most important factor. Ozarslan (2012) confirmed the minimum operating pressure was one of the key parameters for the design of a salt cavern used for hydrogen storage. He pointed out that an excessively low pressure could cause dilatancy, instability, and excessive volume shrinkage. Costa et al. (2011) investigated the feasibility of using the rock salt in deep sea for natural gas and $\mathrm{CO}_{2}$ storage, and indicated that the minimum gas pressure should be no less than $50 \%$ of the original in-situ stress at the cavern roof to maintain the cavern long-term stability. Ma et al. (2015) built a yield-dilatancy-failure model to determine the minimum gas pressure for Jianghan salt cavern UGS, Hubei province,
China, under emergency condition. Mahmoudi et al. (2015) confirmed that the low operating pressure of a salt cavern used for gas and hydrogen storage directly determined whether dilatancy, spalling, and casing damage might happen, and is one of the parameters that should be selected cautiously. Belzer and DeVries (2017) studied the effects of cavern depth, diameter, roof shape, minimum operating pressure, and rock salt properties on the safety of completion casing of a salt cavern UGS, and found roof shape and minimum operating pressure had notable influences on casing safety. Chen et al. (2018) studied the healing effectiveness of rock salt cracks affected by the applied stresses and time and found there is a damage threshold for salt cracks healing ability. Wang et al. (2018a) optimized the design parameters of China's first salt cavern UGS in an ultra-deep formation with a depth more than $-1800 \mathrm{~m}$, and indicated that the minimum gas pressure was one of the most difficult parameters to determine. From the above review, it is clear that the minimum operating gas pressure for a salt cavern used for energy storage is still of great concern. Geomechanical investigations are one of the most powerful tools to address this problem. They will be used in this paper.

The main motivation for this paper is to find the minimum allowable gas pressure and its maximum duration for Jintan salt cavern UGS under an emergency. KING-1 and 2 caverns are simulated as an example. By using the geological features and rock properties of the host salt formation and the dimensions of KING-1 and -2 caverns, a 3D geomechanical model is established. The responses of the rock mass around the caverns and casing shoe under different extreme low gas pressures are investigated. Criteria for evaluating the safeties of completion casing and cavern are proposed. The safeties of casing and cavern under different conditions are discussed. The minimum allowable gas pressure and its maximum duration for KING-1 and -2 caverns are proposed. Research results can provide a reference for the decision-making for Jintan salt cavern UGS encountered the natural gas shortage.

\section{Geomechanical model and boundary conditions}

\subsection{Background of KING-1 and -2 caverns}

Jintan salt cavern UGS is China's first salt cavern UGS. Its construction began in 2000. Its first cavern was completed and operated with gas injection in 2010. By the end of 2017, about 30 caverns had been constructed and were operating. By analyzing the sonar survey data of more than 10 caverns, we know that the volume shrinkages of Jintan salt caverns are small, and the cavern shapes change only slightly (Yang et al., 2015a, b). This indicates that Jintan rock salt has a good capacity to resist creep deformation and accelerated creep does not take place under currently used gas pressures. It also shows that Jintan salt cavern UGS has a good feasibility to increase the working gas capacity by decreasing the operating pressure. The caverns of Jintan UGS consist of abandoned caverns formed by 
brine production (about six caverns) and caverns newly constructed for gas storage (about 24 caverns). Due to those abandoned caverns formed by brine production not having been constructed based on the requirements of a cavern used for gas storage, they usually have poor shapes and small pillar widths (Yang et al., 2015b). If those old caverns were selected as the study target in the paper, the calculation results would lose their representativeness and universality. Therefore, two newly constructed caverns are selected as the study target, viz., KING-1 and -2 caverns. The distance between the well heads of the two caverns is about $263 \mathrm{~m}$. The width of the pillar between them is about $183 \mathrm{~m}$, about 2.3 times the cavern maximum diameter. Table 1 lists background information about KING-1 and 2 caverns.

Figure 1 presents the shapes of KING-1 and -2 caverns obtained by sonar survey. The two caverns both have regular shapes, and are basic rotational bodies.

\subsection{Mechanical and creep properties of rocks}

Wuhan Institute of Rock and Soil Mechanics, Chinese Academy of Sciences, one of the departments responsible for the construction of Jintan salt cavern UGS, had obtained more than $500 \mathrm{~m}$ of cores from three wells. Systematic rock mechanical, physical and creep tests have been carried out and numerous test data had been obtained (Yang et al., 2009, 2015a, b). Those data had been used in the design, construction, operation and safety evaluation of Jintan salt cavern UGS, and had been well verified (Yang et al., 2009, 2015a, b). Because those testing procedures, results, and observations have been published, they are not repeated here. Based on the geological characteristics of the target salt formation, three kinds of rock will be used in the construction of the 3D geomechanical model. They are mudstone, rock salt and interlayers. Their mechanical properties are listed in Table 2 (Yang et al., 2009, 2015a, b).
The creep test results of Jintan rock salt indicate that the transient creep stage takes place within several hours (Guo et al., 2012; Li et al., 2014). The steady creep stage lasts a long time, which is main stage of the creep. The accelerated stage is seldom observed in the tests, and will not be permitted to take place for an actual engineering. Therefore, only the steady creep of Jintan rock salt is simulated. The creep of Jintan rock salt fits well to the NortonHoff steady creep model, which has been verified by field monitoring data with a high reliability and precision (Yang et al., 2015a, b). Therefore, the Norton-Hoff steady creep model is also used in this paper to depict the creep of Jintan rock salt. It is expressed as (Yang et al., 2015a, b):

$$
\dot{\varepsilon}=A \cdot(\bar{\sigma})^{n},
$$

where $\dot{\varepsilon}$ is the steady creep rate of rock salt; $A$ is a material constant; $\bar{\sigma}$ is the normal stress to which the sample is subjected, defined as the difference between the vertical stress and the confining pressure; $n$ is the stress index, usually valued as $3 \sim 6$ for rock salt (Bérest et al., 2001).

Based on previous test results (Yang et al., 2015b), mudstone does not exhibit creep, and the creep parameters of rock salt and interlayer of the target formation are, Rock salt : $A=2.996 \times 10^{-9} \mathrm{MPa}^{-4.480} / a, n=4.480 ; \quad$ Interlayer : $A=12.0 \times 10^{-6} \mathrm{MPa}^{-3.5} / a, \quad n=3.5$.

\subsection{Geomechanical model and boundary conditions}

To investigate the responses of rock mass around and completion casing of KING-1 and -2 caverns under different extreme low gas pressures, a 3D geomechanical model is established based on the geological characteristics of the target formation and sonar survey data of the two caverns. Figure 2 presents the 3D geomechanical model and boundary conditions of KING-1 and -2 caverns. Considering the shapes of KING-1 and -2 caverns have good symmetry

Table 1. Background information about KING-1 and -2 caverns.

\begin{tabular}{lcc}
\hline Cavern & KING-1 & KING-2 \\
\hline Items & & September 2005 \\
\hline Drilling completion & September 2005 & $-1137 \mathrm{~m}$ \\
Drilling depth & $-1145 \mathrm{~m}$ & July 2012 \\
Cavern leaching completion & March 2011 & August 2015 \\
Debrining completion & December 2011 & $18.97 \times 10^{4} \mathrm{~m}^{3}$ \\
Volume & $19.38 \times 10^{4} \mathrm{~m}^{3}$ & $3355 \times 10^{4} \mathrm{~m}^{3}$ \\
Max. gas capacity & $3481 \times 10^{4} \mathrm{~m}^{3}$ & $2059 \times 10^{4} \mathrm{~m}^{3}$ \\
Max. working gas capacity & $2137 \times 10^{4} \mathrm{~m}^{3}$ & $7 / 17 \mathrm{MPa}^{3}$ \\
Min./max. gas pressure & $7 / 17 \mathrm{MPa}$ & $215 \times 10^{4} \mathrm{~m}^{3} /$ day \\
Max. gas injection/delivery capacity & $215 \times 10^{4} \mathrm{~m}^{3} / \mathrm{day}$ & $-1014 \mathrm{~m}^{3}$ \\
Cavern roof depth & $-1012 \mathrm{~m}$ & $-1078 \mathrm{~m}$ \\
Cavern bottom depth & $-1087 \mathrm{~m}$ & $64 \mathrm{~m}$ \\
Cavern height & $75 \mathrm{~m}$ & $80.6 \mathrm{~m}$ \\
Cavern max. diameter & $80.3 \mathrm{~m}$ & $-996 \mathrm{~m}$ \\
Casing shoe depth & $-996 \mathrm{~m}$ &
\end{tabular}




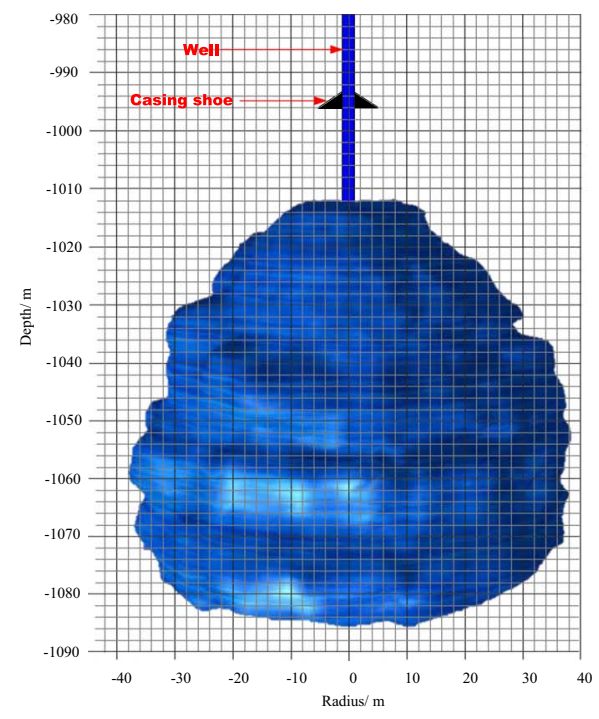

(a) KING-1

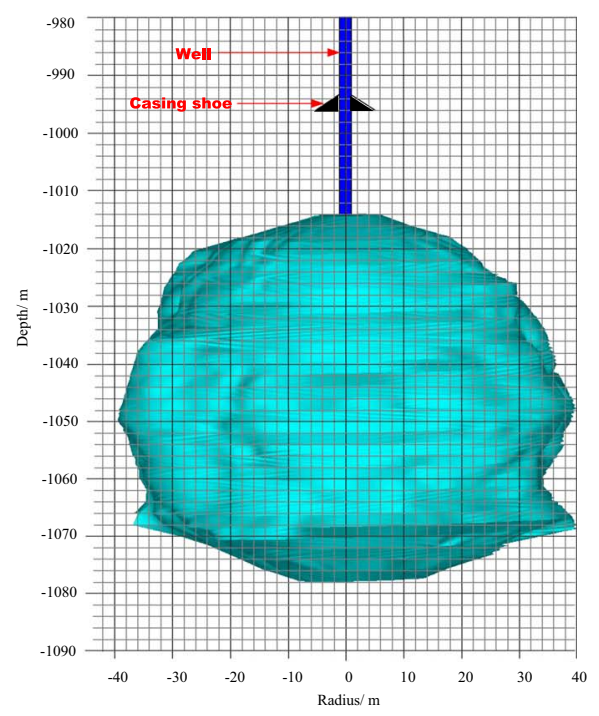

(b) KING-2

Fig. 1. Shapes of KING-1 and -2 caverns obtained by sonar survey.

Table 2. Mechanical properties of rocks used in the numerical simulations.

\begin{tabular}{lccc}
\hline Property & \multicolumn{2}{c}{ Materials } & Mudstone \\
\cline { 2 - 4 } & Rock salt & Interlayer & 4.72 \\
\hline Young's modulus (GPa) & 3.99 & 3.8 & 0.185 \\
Poisson's ratio & 0.24 & 0.277 & 8.19 \\
Cohesion (MPa) & 5.45 & 5.70 & 39.57 \\
Friction angle (degrees) & 30.51 & 30.43 & 1.67 \\
Tensile strength (MPa) & 1.04 & 1.08 & \\
\hline
\end{tabular}

(Fig. 1), only one half of the two caverns is modeled. To clearly show the cavern shape, enlarged views of the two caverns are also included in Figure 2. The irregular sections on the two cavern walls are smoothed. It can ensure that the geomechanical model reflects the caverns' shapes and dimensions as much as possible and that it has a high calculating efficiency. The overall model is a cuboid with dimensions of $1300 \mathrm{~m} \times 400 \mathrm{~m} \times 800 \mathrm{~m}$ in length, width and height. The bedded rock salt formation used for the cavern construction is in the middle of the model. Two compacted mudstone layers are located at the upper and lower edges of the rock salt formation. Based on previous geological exploration, the depths of the rock salt formation roof and bottom are -976 and $-1145 \mathrm{~m}$ respectively, viz., the thickness of the rock salt formation is $169 \mathrm{~m}$. KING-1 and -2 are located at the center of the model. Their dimensions and shapes are given in Section 2.1.

The heights and maximum radii of the two caverns are about 80 and $40 \mathrm{~m}$. The distances between the caverns and model boundaries are all about 10 times the cavern dimensions along their respective directions. This can effectively decrease the influence of boundary effects caused by the geomechanical model size on the numerical results. The width of the pillar between KING-1 and -2 caverns is about
$183 \mathrm{~m}$, about 2.3 times the maximum cavern diameter. It is larger than the average pillar width of Jintan UGS.

The completion casing size of Jintan is $244.5 \mathrm{~mm} \times$ $9.19 \mathrm{~mm}$ (outer diameter and wall thickness), while the diameters and heights of the caverns usually are about 80 and $100 \mathrm{~m}$ (Wang et al., 2018b). If the geomechanical model includes both the completion casing and the cavern, there will be too many elements and nodes. Moreover, the large size differences between those elements may cause non-convergence of the calculation. To ensure the tightness of a salt cavern UGS, the completion casing and the formation are tightly connected by emplacing high grade cement slurry along the entire well. The completion casing is assumed to deform synchronously and equally with the formations (Belzer and DeVries, 2017). The completion casing strain at different locations is obtained by the rock strain at those locations. Therefore, the completion casing and cement sheath are not included in the 3D geomechanical model. The locations of the casing shoes are the most important parameters of the entire completion casing (Fig. 3). Two monitoring points at the two casing shoes are set, and marked as points A and B (Fig. 2) to monitor the casing deformations. Two interlayers pass through the caverns, and their roof depths are -1045 , and $-1068 \mathrm{~m}$, with 


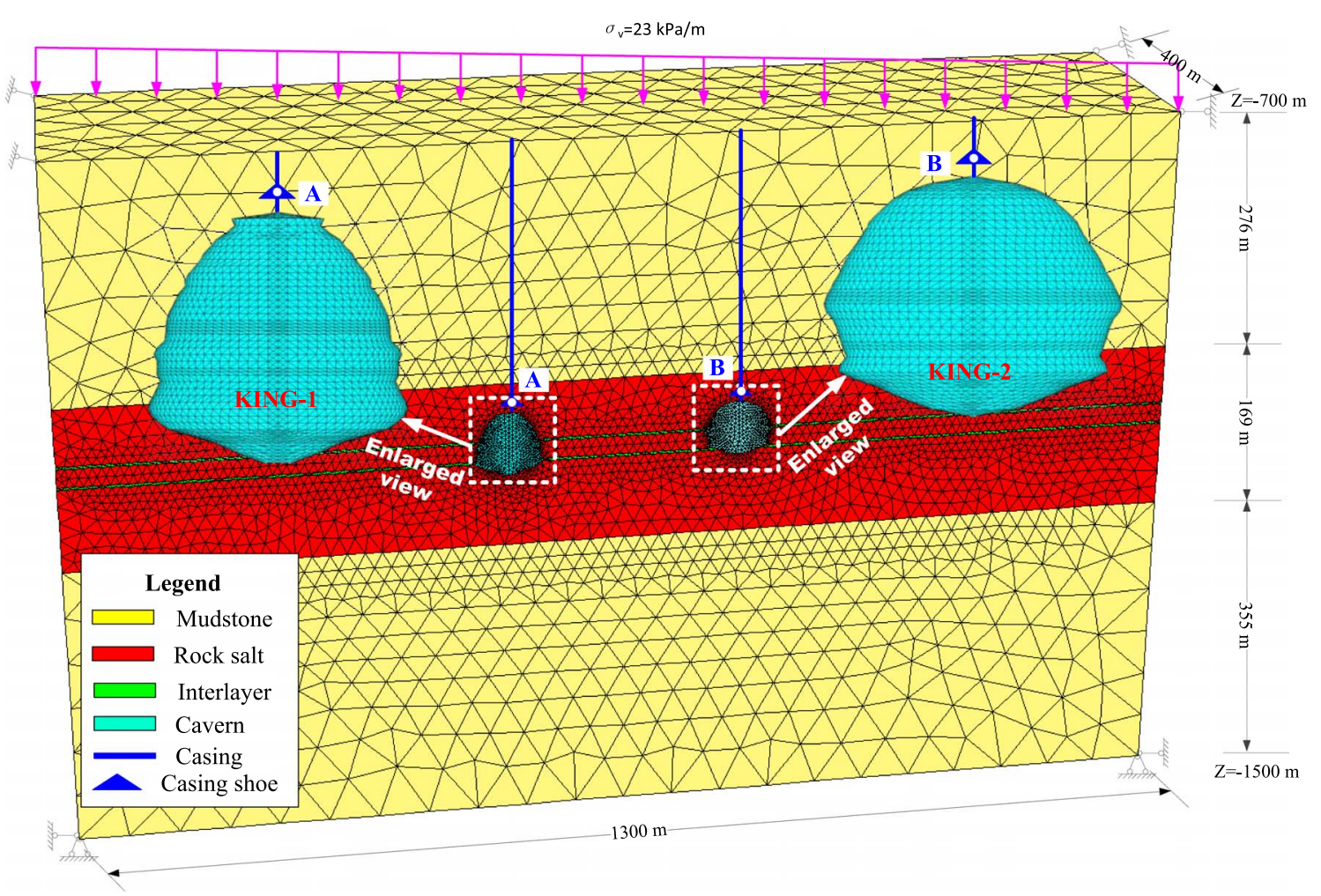

Fig. 2. Geomechanical model and boundary conditions of KING-1 and -2 caverns. To show the shapes of the two caverns clearly, the enlarged views of the two caverns are also presented in the figure.

thicknesses of 2.2 , and $2.4 \mathrm{~m}$ respectively from up to down. A fixed boundary is applied to the cavern bottom to constrain the displacements along all directions. On the four vertical surfaces horizontal displacements are constrained while their vertical displacements are free.

Overburden stress is applied to the top of the model. The overburden stress is calculated from the depth and the average density of the overlying formation. It is about 16.1 $\mathrm{MPa}(23 \mathrm{kPa} / \mathrm{m})$ for this simulation. The initial in-situ stresses and their gradients in the rock salt formation are basically equal along three directions at any given depth (Wang et al., 2019). This is mainly because the good creep deformation of rock salt causes any differential tectonic stresses of the rock salt formation to be released completely during the diagenesis. The cavern construction by water leaching is a continuous and gradual process, which does not have the staged excavation. Therefore, the two caverns are assumed to be excavated instantaneously and simultaneously. To eliminate the simplifying effects of this assumption on the numerical results, the in-situ stress redistribution is calculated after the cavern excavation. Considering the brine fills the entire salt cavern during the construction, the brine hydraulic pressure loads on the cavern wall during the entire construction process. It means the pressure loaded on the cavern wall remains constantly during the entire leaching process. During the stress redistribution calculations, the initial stresses and overlying pressure are loaded on the geomechanical model accordingly while only the brine hydrostatic pressure is loaded on the cavern walls. The redistributed stress is used as the internal initial boundary condition for the later creep calculations. Due to the minimum operating pressures of KING-1 and -2 caverns having been designed initially as $7 \mathrm{MPa}$, the gas pressures are simulated as 6, 5, 4 and $3 \mathrm{MPa}$ to determine the allowable minimum pressure of the two caverns. The gradient of the gas pressure is not considered in the simulations because cavern height is relatively small. Salt caverns are operated with such low gas pressure only for emergency conditions and not for the long-term. Therefore, the duration for the simulation is valued as 0.5 year, viz., about 183 days.

Only the zones around the cavern and casing shoes are of concern. Radial elements are used in the geomechanical model. Elements close to the caverns and casing shoes are small while the sizes of the elements at the other locations increase with increasing distances to the zones of main interest. This ensures the calculating accuracy of the zones of interest and greatly improves the calculating efficiency. To prevent that the element dimensions of different parts of the geomechanical model change too much, tetrahedral, hexahedral, and pyramidal elements are used. Meshtool embedded in $A N S Y S$ software is used to check the mesh quality (ANSYS Inc., 2012) to avoid any adverse impact of a poor mesh quality. Elements with several different sizes have been simulated to make sure that the numerical results are independent of element sizes. The model includes 1183668 elements and 203787 nodes. The sizes of the smallest and largest elements are about $1 \mathrm{~m}$ near the cavern and $10 \mathrm{~m}$ for mudstone layers respectively. FLAC ${ }^{3 \mathrm{D}}$ is used for the calculation for its notable advantage in dealing with large deformation problems of rock and soil engineering (Itasca Consulting Group, 2005; Maji, 2018). Tecplot 


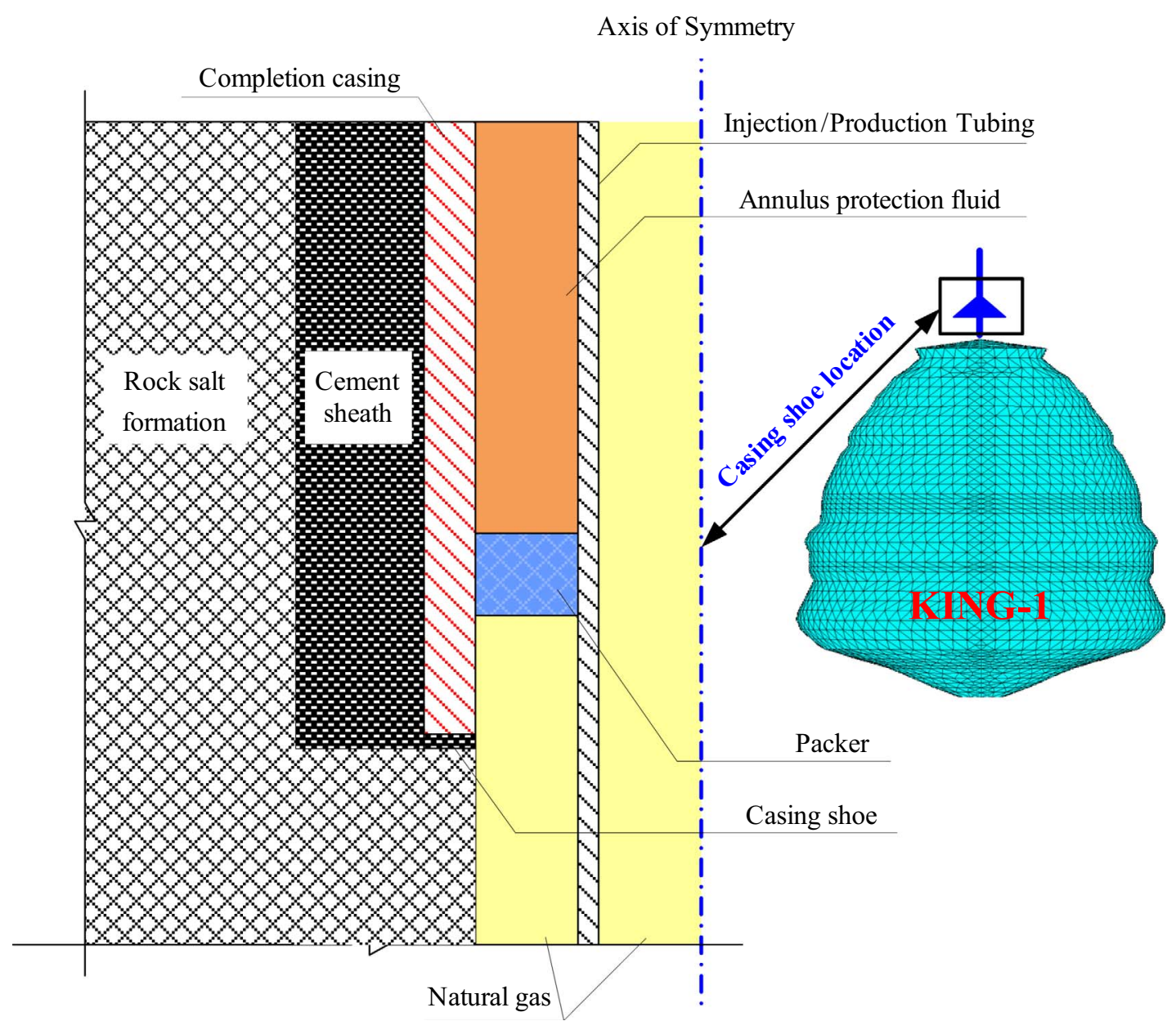

Fig. 3. Schematic diagram of the last completion casing of a salt cavern UGS at the casing shoe location.

(Tecplot Inc., 2013) is used for the post-processing. To ensure the convergence of the calculation, several points are monitored, mainly located at the cavern roof and bottom. The stresses and displacements of those points are obtained. The results indicate that the element type and size used in this paper ensure the numerical simulation convergence.

During the numerical simulation, the coupling of the thermo-mechanical analysis is not considered. There are two reasons. First, many studies (Bérest et al., 2007, 2014; Ngo and Pellet, 2018) show the damages of the rock salt caused by the temperature change have slight effects on the salt cavern stability and only when the caverns have poor shapes (e.g., flat roof, overhanging blocks, or narrow pillar). Second, the critical gas delivery rates rather than the minimum allowable gas pressure and its maximum duration are associated with the thermos-mechanical issue.

\section{Safety evaluation criteria}

The extreme low gas pressure may cause tensile failure of the completion casing and instability of the cavern. Therefore, the safety evaluation criteria from the viewpoints of the completion casing and cavern are proposed, and their definitions and thresholds are given as follows.

\subsection{Criteria for completion casing}

Figure 3 presents a schematic diagram of the last completion casing of a salt cavern UGS at the casing shoe location. The pipe string of a salt cavern UGS is composed of completion casing on the outside and inner gas injection/delivery tubing in the inside. The inner tubing is connected with the completion casing by the packer. Therefore, the failure of the inner tubing will not take place caused by the stress change of the formation, and that is not the study target of this paper. The completion casing is tightly cemented with the host formations, and they can be treated as an integral whole. The deformation of the formation may cause damage of the completion casing. The vertical deformation of the rock mass above the cavern roof is larger than at the other locations. Due to the material difference between salt formation and casing, excessive axial tensile strain may be produced. Once the tensile strain exceeds the threshold, tensile failure takes place in the casing. Therefore, axial tensile strain is selected as the indicator to assess the safety of 


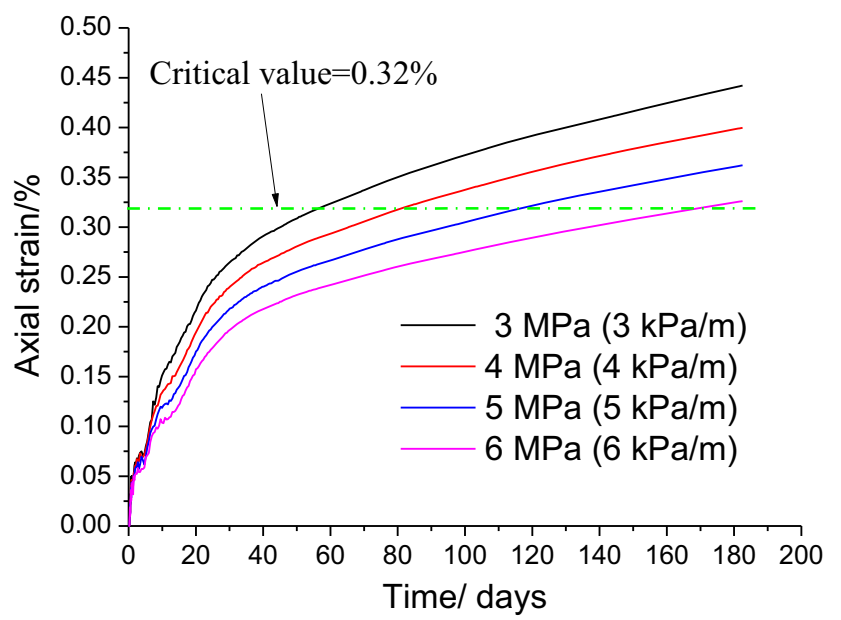

(a) KING-1

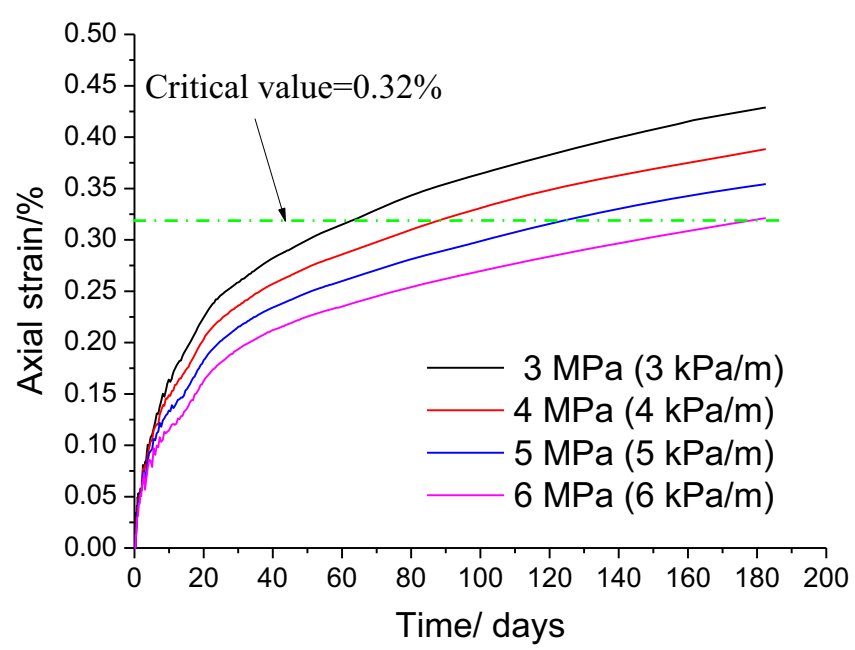

(b) KING-2

Fig. 4. Relations between the axial strains of the completion casing at casing shoe $(-996 \mathrm{~m})$ of KING-1 and -2 caverns and time when the gas pressure is valued differently.

the casing. Figure 3 also indicates that the last casing at the casing shoe is the weakest part of the entire completion casing. This is because the in-situ stresses applied to the last casing are larger than those applied to the other casings. Moreover, the last casing's inner wall is subjected to intermittent loads caused by gas injection and production while the loads applied to the other casing's inner wall basically are constant. Therefore, it is the most critical part to ensure the tightness of a salt cavern UGS. By monitoring the axial tensile stress of the rock salt at the casing shoe, the axial tensile strain (Belzer and DeVries, 2017) subjected to the casing can be calculated as:

$$
\varepsilon_{\text {Axial }}=\frac{\Delta \sigma}{E_{\text {salt }}},
$$

where $\varepsilon_{\text {Axial }}$ is the axial tensile strain to which the completion casing is subjected at the casing shoe location; $\Delta \sigma$ is the vertical stress change in the rock salt at the casing shoe location, MPa; $E_{\text {salt }}$ is the Young's modulus of rock salt, MPa.

The completion casing used for Jintan salt cavern UGS has a diameter of $244.45 \mathrm{~mm}$, a wall thickness of $9.19 \mathrm{~mm}$, and is connected by gas sealing threads. The steel grade is N80. The Young's modulus of Jintan rock salt is $3990 \mathrm{MPa}$. Based on the casing types used in Jintan and available literature (Belzer and DeVries, 2017), equation (3) has to be satisfied to avoid tensile failure of this casing:

$$
\varepsilon_{\text {Axial }} \leq 0.32 \% \text {. }
$$

\subsection{Criteria for salt cavern}

A salt cavern UGS operated at an extremely low pressure has typical seasonal operating mode (usually in winter), and usually is operated at an extremely low pressure only for a short time. The creep deformation failure may have a low probability of happening in such a short time. Damage of the salt cavern may be caused mainly by the stress exceeding the strength of surrounding rock mass under such an extreme low pressure and short time condition. Moreover, there are no reliable criteria for the failure prediction of salt caverns due to the fact that rock salt has the typical characteristic of large plastic deformation capacity (Wang et al., 2015a), damage self-repairing (Chen et al., 2018) and high load-bearing capacity in plastic state. Therefore, a safety criterion composed of displacement, vertical stress, dilatancy safety factor, and plastic zone is proposed to assess the cavern safety, which can decrease the risk by using only one indicator. Those indicators are mainly calculated by the stress as the benchmark. Only one indicator calculated by the deformation as the benchmark is included. The definitions and thresholds of the indicators are as follows.

\subsubsection{Displacement}

Based on the previous research, the maximum displacement of Jintan salt cavern UGS should be no more than $5 \%$ of the cavern maximum diameter over the entire service lifetime (usually 30 years) to prevent spalling, roof fall, and sluffing (Wang et al., 2016). The direction of the displacement is perpendicular to the cavern wall. The displacement thresholds for KING-1 and -2 caverns are $4 \mathrm{~m}$, calculated based on their maximum diameters (see Tab. 1).

\subsubsection{Vertical stress}

The cavern walls are in direct contact with the gas, and the gas pressure change over time causes a change of the stress in the rock around the cavern. Stress concentrations form around the interlayers and the locations with size change. Local damage may happen at those stress concentration zones. Therefore, vertical stress is selected as one indicator.

\subsubsection{Dilatancy safety factor}

It indicates that the failure of rock salt is determined by a combination of the first principal stress invariant and the second principal stress deviation (Van Sambeek et al., 


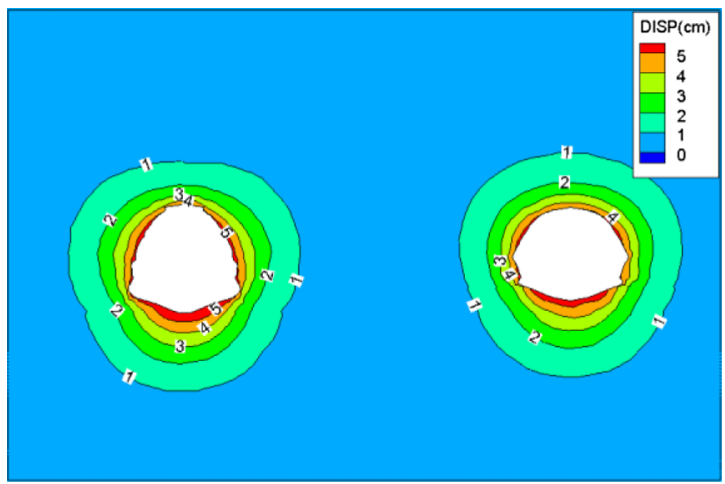

(a) $3 \mathrm{MPa}$ and 57 days

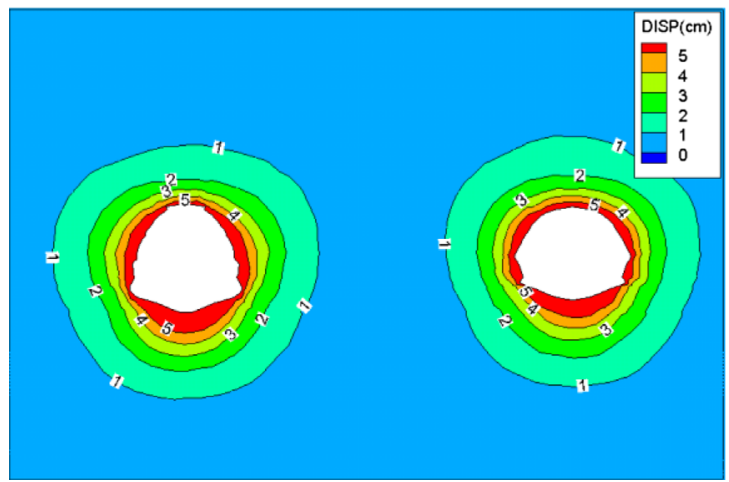

(c) $5 \mathrm{MPa}$ and 118 days

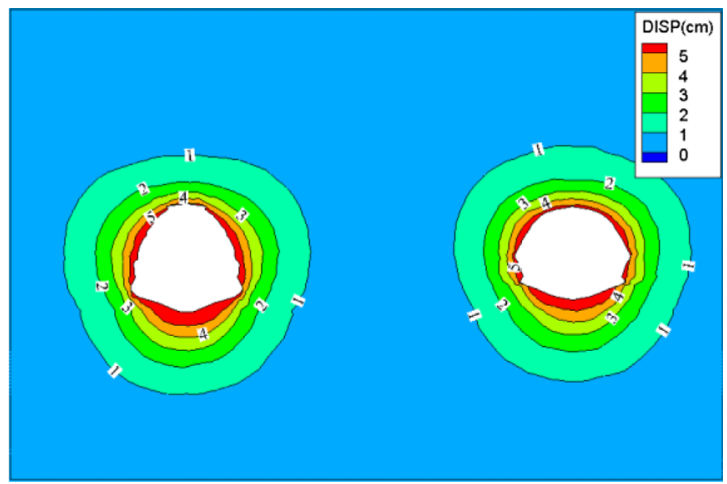

(b) $4 \mathrm{MPa}$ and 80 days

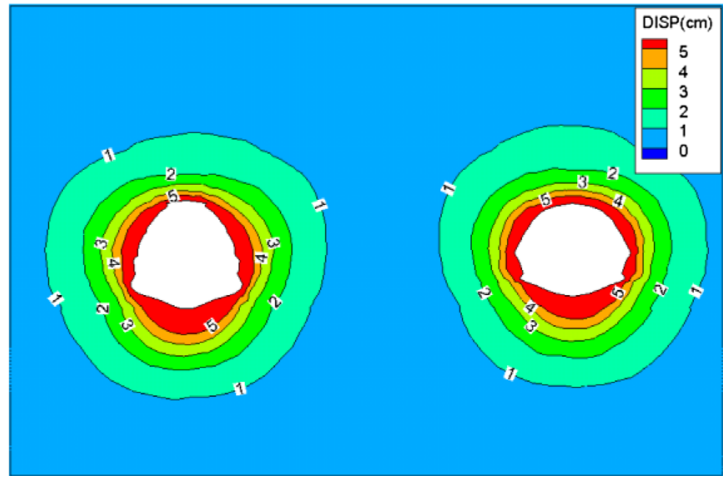

(d) $6 \mathrm{MPa}$ and 170 days

Fig. 5. Displacement of rock mass around KING-1 and -2 caverns on the vertical section under four different operating conditions.

1993), and is an indicator calculated from the stresses as the benchmark. This criterion has been widely used in and verified by the design and safety evaluation of salt caverns used for oil and gas storage (Sobolik and Ehgartner, 2006). Based on previous test results of bedded rock salt of Jintan district, Jiangsu province, China (Yang et al., 2015a), the Van Sambeek criterion best matches the experimental results among available criteria. It is expressed as:

$$
\mathrm{SF}_{v s}=\frac{0.27 I_{1}}{\sqrt{J_{2}}},
$$

where $\mathrm{SF}_{v s}$ is the safety factor for dilatancy; $I_{1}$ is the first invariant of the stress tensor, $I_{1}=\sigma_{1}+\sigma_{2}+\sigma_{3} ; J_{2}$ is the second invariant of the deviatoric stress tensor, $J_{2}=\frac{1}{6}$ $\left[\left(\sigma_{1}-\sigma_{2}\right)^{2}+\left(\sigma_{2}-\sigma_{3}\right)^{2}+\left(\sigma_{3}-\sigma_{1}\right)^{2}\right] . \sigma_{1}, \sigma_{2}, \sigma_{3}$ are the first, second, and third principal stresses. Dilatancy safety factor smaller than 0.6 indicates collapse, ranging from 0.6 to 1.0 indicates failure, and ranging from 1.0 to 1.5 indicates local damage (Wang et al., 2016). Those thresholds are used to determine the allowable minimum gas pressure of Jintan salt cavern UGS.

\subsubsection{Plastic zone}

Considering its simple expression, easily solved by a computer program, and widely used in rock and soil engineering (Shen et al., 2018; Yang et al., 2016), Mohr-Coulomb criterion is selected as one indicator to predict the cavern safety.
The width of the plastic zone accounting for no more than $50 \%$ of the pillar width is proposed as the threshold (Wang et al., 2015b).

\section{Analysis of results and discussions}

\subsection{Completion casing}

Figure 4 presents the relations between the axial strains of the completion casing at casing shoe $(-996 \mathrm{~m})$ of KING-1 and -2 caverns and time when the gas pressure is valued as 3, 4, 5, and $6 \mathrm{MPa}$, viz., the gas pressure gradients are about $3,4,5$, and $6 \mathrm{kPa} / \mathrm{m}$ at casing shoe depth respectively. The axial strains increase with time and decrease with increasing gas pressures. The axial strains increase fast at the beginning, and then trend to a constant. The axial strain trending to a constant at a high gas pressure takes less time than that at a low pressure. This indicates that a low gas pressure will cause the completion casing damage in a short time. Based on the results in Figure 4 and the threshold in Section 3.1, the safe operating time of KING1 and -2 caverns under $3,4,5$, and $6 \mathrm{MPa}$ are no more than $57,80,118,170$ days, and 62, 88, 125, 178 days respectively. Compared with KING-1 cavern, KING-2 has an advantage in protecting the completion casing safety. This may be because (i) the cavern roof shape of KING-2 is more suitable for bearing loads than that of KING-1 cavern; (ii) the distance between the casing shoe and the cavern roof 


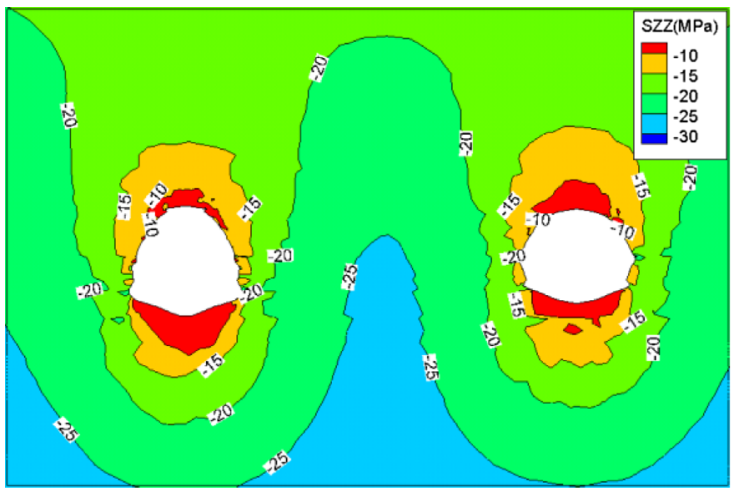

(a) $3 \mathrm{MPa}$ and 57 days

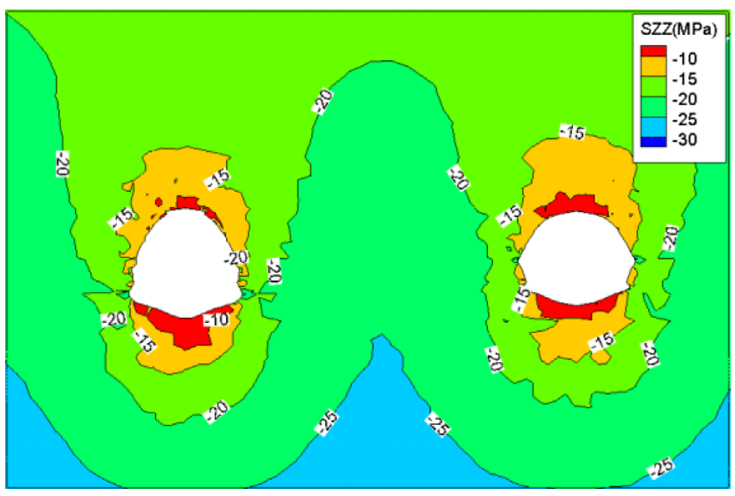

(c) $5 \mathrm{MPa}$ and 118 days

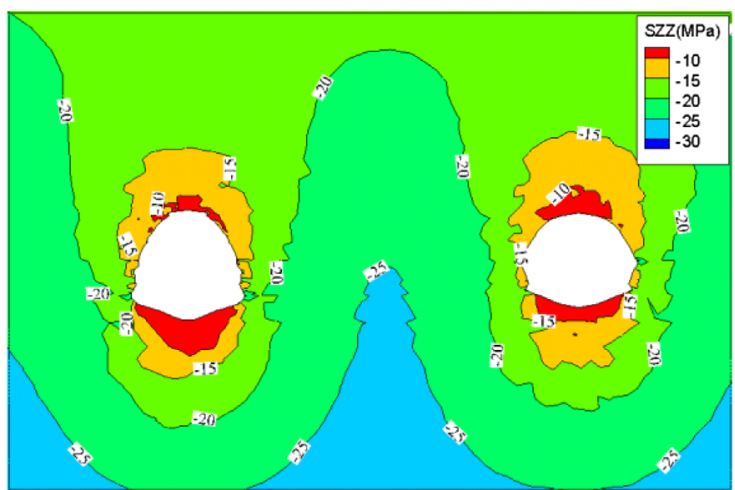

(b) $4 \mathrm{MPa}$ and 80 days

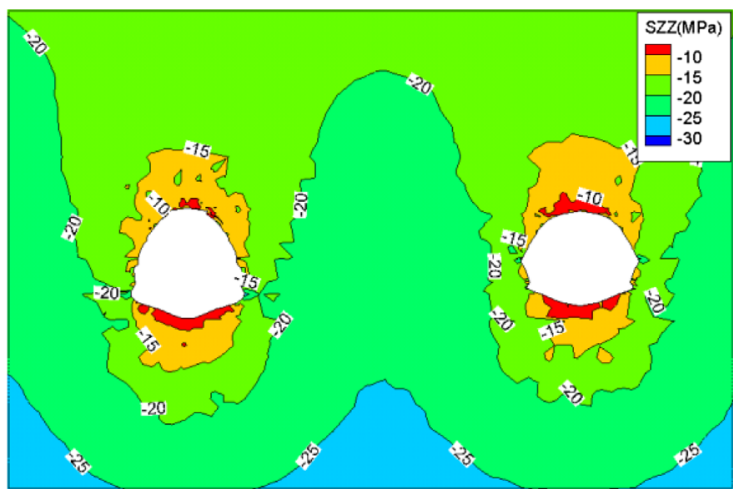

(d) $6 \mathrm{MPa}$ and 170 days

Fig. 6. Vertical stresses of rock mass around KING-1 and -2 caverns on the vertical section under four different operating conditions.

of KING-2 $(18 \mathrm{~m})$ is larger than that $(16 \mathrm{~m})$ of KING-1 cavern. Because KING-1 and -2 are neighbors, we recommend that the allowable minimum operating parameters are valued as those of KING-1 cavern, viz., the two caverns are operated with $3,4,5$, and $6 \mathrm{MPa}$ gas pressures for no more than $57,80,118,170$ days, respectively.

\subsection{Salt cavern}

Based on the results of Section 4.1, four critical operating conditions have been considered, viz., operating pressure and time of (i) $3 \mathrm{MPa}$ and 57 days; (ii) $4 \mathrm{MPa}$ and 80 days; (iii) $5 \mathrm{MPa}$ and 118 days; and (iv) $6 \mathrm{MPa}$ and 170 days. Therefore, these four operating conditions are used in this section as the internal boundary conditions to verify the safety of the two caverns. Figure 5 presents the displacement of the rock mass around KING-1 and -2 caverns on the vertical section under four different operating conditions. The displacement is the vector sum of the displacements along $x, y$, and $z$ directions. The displacements for the four conditions increase gradually with time. The displacement of the rock mass around an UGS salt cavern decreases with increasing gas pressure, and increases with time (Yang et al., 2015a, 2016). For the four conditions, the displacements increased gradually with time. This indicates that the increase of the displacement caused by time is larger than the decrease of displacement caused by the increasing gas pressure. Calculation results also show that the KING-1 cavern has better capacity in resisting deformation than KING-2 cavern. Based on the displacement threshold in Section 3.2, the two caverns are both in a safe state. Moreover, the maximum displacements of the two caverns are all at the centimeter level, much smaller than the critical value of $4 \mathrm{~m}$. This indicates that the two caverns have a high safety level.

Figure 6 presents the vertical stresses around KING-1 and -2 caverns on the vertical section under four different operating conditions, where the compressive stress is defined as negative. The initial in-situ stresses of the locations of the caverns are about $-23 \mathrm{MPa}$. Due to the presence of the cavern, stresses are redistributed. The small vertical stress zones (red) mean the zones are subjected to high deviatoric stress (the difference between the horizontal in-situ stress and the vertical stress), and there, damage is more likely to happen. The red zones are mainly concentrated at the cavern roof and bottom. When the gas pressure and time increase, the areas of the red zones decrease, which indicates that the safety of the cavern improves. This is because the increasing gas pressure balances some of the far field in-situ stress and the creep of rock salt transfers the stress from the high stress zone to the low stress zone. This makes the stress in the rock mass around the cavern more uniform, and hence the cavern becomes safer. By comparing the results of Figures $6 \mathrm{a}-6 \mathrm{~d}$, 


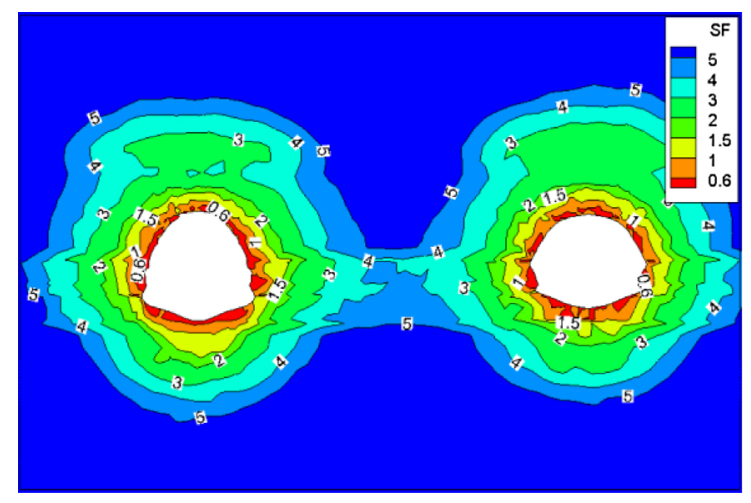

(a) $3 \mathrm{MPa}$ and 57 days

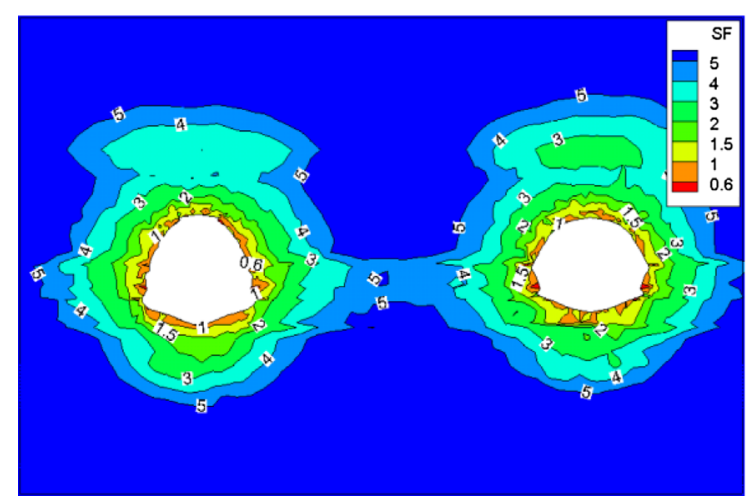

(c) $5 \mathrm{MPa}$ and 118 days

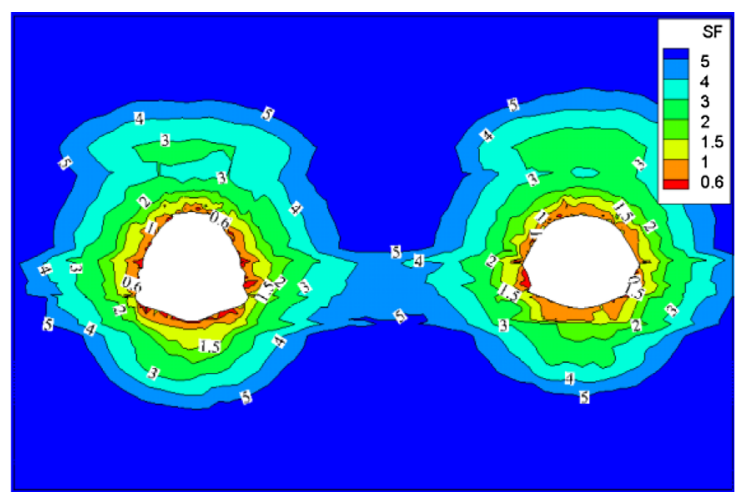

(b) $4 \mathrm{MPa}$ and 80 days

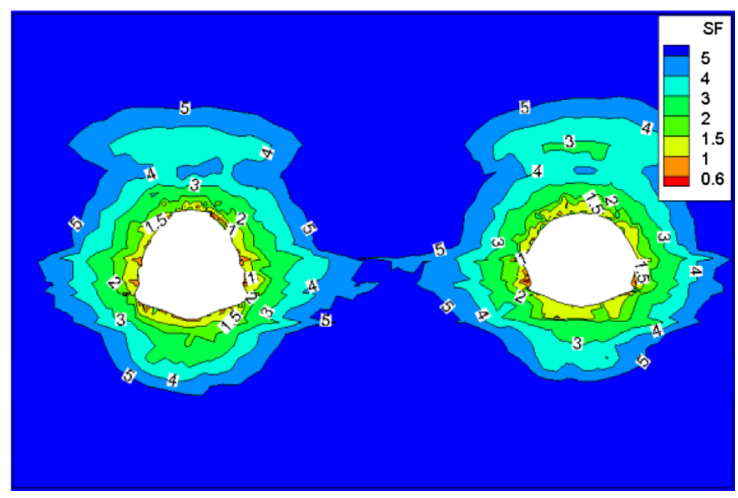

(d) $6 \mathrm{MPa}$ and 170 days

Fig. 7. Dilatancy Safety Factors (SF) of rock mass around KING-1 and -2 caverns on the vertical section obtained by equation (4) under four different operating conditions.

the red zones nearly do not exist in the pillar under all four conditions, and the stresses in the pillar become more uniform with the increase of gas pressure and of time. Because there is no clear safe threshold, the quantitative assessment of KING-1 and -2 cannot be given from the viewpoint of vertical stress. From the areas of the red zones, Figures $6 \mathrm{a}$ and $6 \mathrm{~b}$ may indicate a large failure risk. If the minimum operating pressure decreases to below $5 \mathrm{MPa}$, more monitoring is proposed, such as micro-seismic monitoring.

Figure 7 presents the dilatancy safety factors of the rock mass around KING-1 and -2 caverns on the vertical section obtained by equation (4) under the four different operating conditions. The zones with dilatancy safety factor smaller than 0.6 have a large area in Figure $7 \mathrm{a}$, and are located mainly at the cavern edges. This suggests that in these zones collapse may take place. In Figure $7 \mathrm{~b}$, the red zone sporadically appears at the cavern edges, and mainly is centralized at the interlayers, indicating that at these zones local damages may happen, such as, spalling, falling, and sluffing. Those local damage zones constrained by adjacent rock masses will remain in their original locations rather than falling down, which may not seriously affect the safety of the entire caverns. The red zone basically disappears in Figures $7 \mathrm{c}$ and $7 \mathrm{~d}$. The cavern has high safety under these conditions. Moreover, the dilatancy safety factors of the pillars between KING-1 and -2 are high under all four conditions. The widths of the zone with dilatancy safety factors smaller than 1.5 account for about $20 \%$ of the pillar width, indicating that the pillar has a relative high safe level. This is because this pillar between the two caverns is very wide (about 2.3 times cavern maximum diameter). Such low operating pressure and short operating time condition have slight effect on the stress redistribution in the pillar. Based on our previous research (Wang et al., 2017; Yang et al., 2015a, 2016), the dilatancy safety factor of rock masses around the salt cavern UGS increases with increasing gas pressure and time. However, the dilatancy safety factor increases greatly for the four conditions that the gas pressure and operating time both increase. Hereby, we conclude that low gas pressure is much more harmful to the cavern stability than the operating time under such low gas pressure and short time conditions. When a scheme is formulated to counter such extreme condition, we propose to put the gas pressure as one of the most critical factors. From the viewpoint of dilatancy safety factor, KING-1 and -2 can be operated safely with a gas pressure of $5 \mathrm{MPa}$ for a duration not exceeding 118 days.

Figure 8 presents the plastic zone (red) around KING-1 and -2 caverns on the vertical section under the four different operating conditions. These plastic zones are mainly distributed at the cavern edges. Interlayers have no significant effects on the plastic zones. The plastic zone areas account 


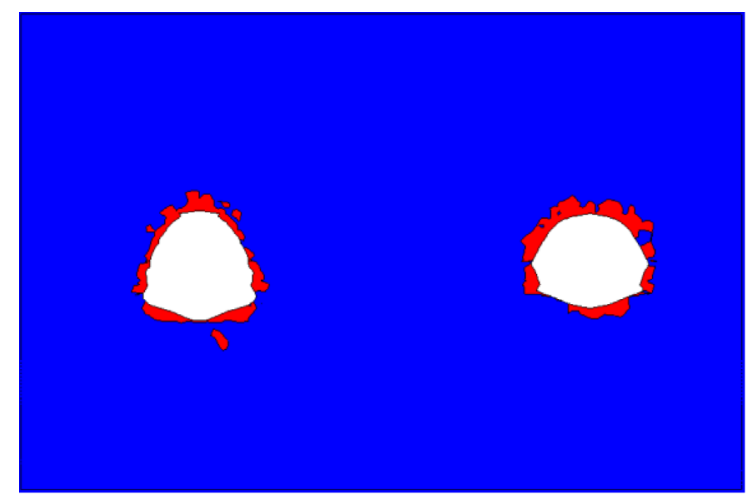

(a) $3 \mathrm{MPa}$ and 57 days

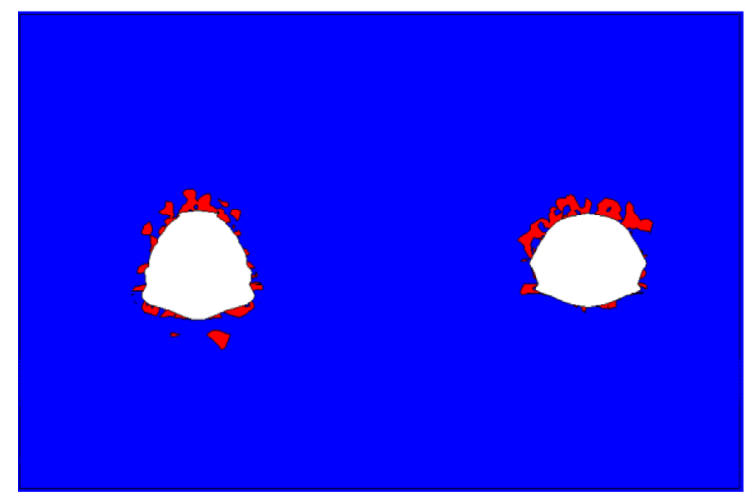

(c) $5 \mathrm{MPa}$ and 118 days

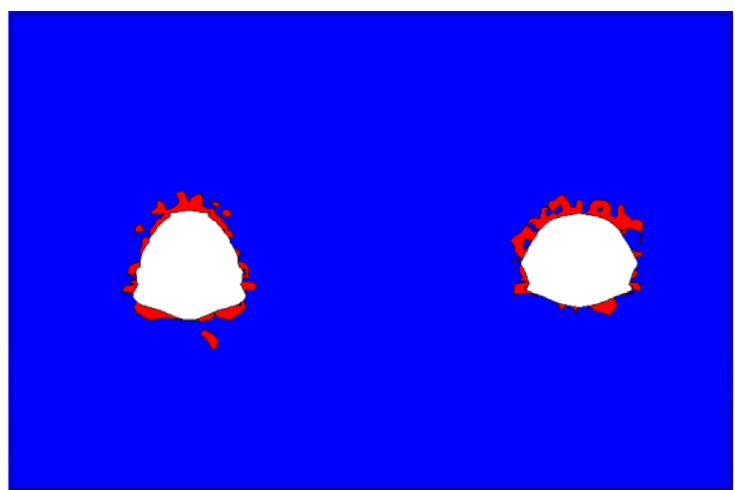

(b) $4 \mathrm{MPa}$ and 80 days

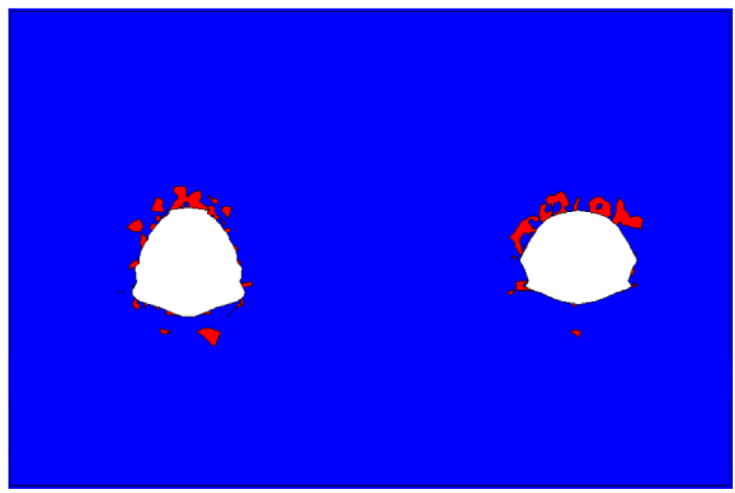

(d) $6 \mathrm{MPa}$ and 170 days

Fig. 8. Plastic zone (red) of rock mass around KING-1 and -2 caverns on the vertical section under four different operating conditions.

for only a small portion of the pillar, showing that the pillar has a high safety level. By comparing the results of Figures $8 \mathrm{a}-8 \mathrm{~d}$, the plastic zone decreases slightly when the gas pressure and operating time increase. The plastic zone in the cavern bottom decreases more than that in the cavern roof. In Figure 8a, the plastic zone in the cavern roof forms a connected area. When local damage happens, massive collapse will take place under the self-weight. In Figure 8b, the plastic zone decreases and is broken up into several pieces. The two caverns both have dome roofs which will constrain the roof falling. The plastic zone in Figures $8 \mathrm{c}$ and $8 \mathrm{~d}$ decreases further and the red zone breaks up into more individual areas, indicating that the local damage risk is low. From the viewpoint of plastic zones, KING-1 and -2 caverns can be operated safely with a $4 \mathrm{MPa}$ gas pressure but for not more than 80 days. This indicates that the plastic zone indicator is risky compared with the dilatancy factors.

By above analysis of the safety of the completion casing and salt cavern under different extremely low gas pressures and for different durations, the minimum gas pressure gradient of KING-1 and -2 caverns at casing shoe can decrease from about $7 \mathrm{kPa} / \mathrm{m}$ to $5 \mathrm{kPa} / \mathrm{m}(7$ to $5 \mathrm{MPa})$ to counter the gas shortage. It means that the ratio between the minimum gas pressure gradient and the overburden gradient at the casing shoe decreases from about $30.4 \%$ to $21.7 \%$. The two caverns can remain safe under a $5 \mathrm{MPa}$ gas pressure for 118 days. Taking KING-1 cavern as an example, the working gas capacity can be increased by more than $3.7 \times 10^{6} \mathrm{~m}^{3}$, an increase of about $17.3 \%$, when the minimum gas pressure gradient decreases from about $7 \mathrm{kPa} / \mathrm{m}$ to $5 \mathrm{kPa} / \mathrm{m}$. If this scheme can be applied to the 30 caverns of Jintan, more than $8.0 \times 10^{7} \mathrm{~m}^{3}$ gas can be used, which will be valuable.

\section{Summary and conclusion}

1. A 3D geomechanical model is established to investigate the responses of KING-1 and -2 caverns to different extremely low operating pressures. A safety evaluation criterion consisting of axial strain of casing, displacement, vertical stress, dilatancy safety factor, and plastic zone of cavern is proposed. The safety of KING-1 and -2 caverns is assessed using the proposed criterion.

2. Calculation results show that the indicators calculated by the stress as the benchmark (such as vertical stress, dilatancy safety factor) are better than those calculated by the deformation (such as displacement) as the benchmark in evaluating the safety of salt caverns under such extremely low pressure and short operating time condition. 
3. By evaluating the safety of the completion casing and caverns, KING-1 and -2 caverns can decrease their minimum gas pressure gradient at the casing shoe from about $7 \mathrm{kPa} / \mathrm{m}$ to about $5 \mathrm{kPa} / \mathrm{m}$. The safe operating time is no more than 118 days under such low pressure. Taking KING-1 cavern as an example, the working gas capacity can increase by about $17.3 \%$.

Acknowledgments. The authors wish to acknowledge the financial supports of National Natural Science Foundation of China (CN) (Grant No. 42072307), Youth Innovation Promotion Association CAS (Grant No. 2016296), and Innovative Research Group Project of the National Natural Science Foundation of China (CN) (Grant No. 51621006).

\section{References}

Adams J. (1997) Natural gas salt cavern storage operating pressure determination, in: Technical Meeting/Petroleum Conference of the South Saskatchewan Section, 19-22 October, Regina, Saskatchewan.

ANSYS Inc. (2012) ANSYS 14.5 mechanical APDL verification manual, Canonsburg, Pennsylvania, USA. http://www. ansys.com.

Bayram F., Bektasoglu I. (2020) Determination of actual dissolution rates from some rock properties in construction of deep salt cavern for natural gas storage, Int. J. Rock Mech. Min. 126, 104183.

Belzer B.E., DeVries K.L. (2017) Numerical prediction of tensile casing failure by salt creep for evaluating the integrity of cemented casings of salt caverns, in: SMRI Spring 2017 Technical Conference, 23-26 April 2017, Albuquerque, New Mexico.

Bérest P., Brouard B. (2003) Safety of salt caverns used for underground storage. Blow out; mechanical instability; seepage; cavern abandonment, Oil Gas Sci. Technol. - Rev. IFP Energies nouvelles 58, 3, 361-384.

Bérest P., Bergues J., Brouard B., Durup J., Guerber B. (2001) A salt cavern abandonment test, Int. J. Rock Mech. Min. 38, 3, 357-368.

Bérest P., Karimi-Jafari M., Brouard B. (2007) Thermal effects in salt caverns, in: Proc. SMRI Spring 2007 Conference, 29 April-2 May 2007, Basel, Switzerland.

Bérest P., Brouard B., Djizanne H., Hévin G. (2014) Thermomechanical effects of a rapid depressurization in a gas cavern, Acta Geotech. 1, 9, 181-186.

Chen J., Kang Y., Liu W., Fan J., Chemenda A. (2018) Selfhealing capacity of damaged rock salt with different initial damage, Geomech. Eng. 15, 1, 615-620.

Chen J., Lu D., Liu W., Fan J., Jiang D., Yi L., Kang Y. (2020) Stability study and optimization design of small-spacing twowell (SSTW) salt caverns for natural gas storages, J. Energy Storage 27, 101131.

Costa A.M., Amaral C.S., Poiate E., Pereira A.M.B., Martha L. F., Gattass M. (2011) Underground storage of natural gas and $\mathrm{CO}_{2}$ in salt caverns in deep and ultra-deep water offshore Brazil, in: 12th ISRM International Congress on Rock Mechanics, October 17-21, 2011, Beijing, PR China, pp. 1659-1664.

Crotogino F., Huebner S. (2008) Energy storage in salt caverns: Developments and concrete projects for adiabatic compressed air and for hydrogen storage, in: SMRI Spring 2008 Technical Conference, 28-29 April 2008, Porto, Portugal.

DeVries K.L., Nieland J.D. (1999) Feasibility study for lowering the min. gas pressure in solution-mined caverns based on geomechanical analyses of creep-induced damage and healing, in: SMRI Spring 1999 Meeting, 11-14 April 1999, Las Vegas, Nevada, USA.

Guo Y., Yang C., Mao H. (2012) Mechanical properties of Jintan mine rock salt under complex stress paths, Int. J. Rock Mech. Min. 56, 54-61.

Itasca Consulting Group (2005) Inc FLAC ${ }^{3 D}$ version 3.0 users' manual (2005), Minneapolis, Minnesota, USA.

Li Y., Liu W., Yang C., Daemen J. (2014) Experimental investigation of mechanical behavior of bedded rock salt containing inclined interlayer, Int. J. Rock Mech. Min. 69, 3949 .

Ma H., Yang C., Li Y., Shi X., Liu J., Wang T. (2015) Stability evaluation of the underground gas storage in rock salts based on new partitions of the surrounding rock, Environ. Earth Sci. 73, 11, 6911-6925.

Mahmoudi E., Khaledi K., König D.I.D. (2015) Numerical simulation of deep and shallow energy storage systems in rock salt, in: Aktuelle Forschung in der Bodenmechanik 2015, Springer, Berlin, Heidelberg, Vol. 2015, pp. 69-83.

Maji V. (2018) Numerical analysis of Shiobara hydropower cavern using practical equivalent approach, J. Rock Mech. Geotech. Eng. 10, 402-410.

Ngo D.T., Pellet F.L. (2018) Numerical modeling of thermallyinduced fractures in a large rock salt mass, J. Rock Mech. Geotech. Eng. 10, 5, 844-855.

Ozarslan A. (2012) Large-scale hydrogen energy storage in salt caverns, Int. J. Hydrogen Energy 37, 19, 14265-14277.

Shen B., Shi J., Barton N. (2018) An approximate nonlinear modified Mohr-Coulomb shear strength criterion with critical state for intact rocks, J. Rock Mech. Geotech. Eng. 10, 645652 .

Sobolik S., Ehgartner B. (2006) Analysis of shapes for the strategic petroleum reserve, Sandia National Laboratories, Albuquerque, NM, USA. No. SAND 2006-3002.

Stone H.B.J., Veldhuis I., Richardson R.N. (2009) Underground hydrogen storage in the UK, Geol. Soc. Lond. Special Publ. 313, 1, 217-226.

Tecplot Inc. (2013) Tecplot 360 user's manual (2013), Bellevue, WA, USA. https://www.scc.kit.edu/downloads/sca/tpum. pdf.

Van Sambeek L., Ratigan J., Hansen F. (1993) Dilatancy of rock salt in laboratory test, in: Haimson B.C. (ed), Proceedings, 34 th U.S. Symposium on Rock Mechanics, June 27-30, University of Wisconsin-Madison, Madison, WI, Int. J. Rock Mech. Min. Sci. Geo. Abst. 1993, Vol. 30, pp. 735-738.

Wang T., Yan X., Yang X., Yang H. (2010) Numerical stimulation of min. permitted operating pressure of natural gas storage in bedded salt, in: 5th International Symposium on In-Situ Rock Stress, August 25-27 2010, Beijing, China, pp. 425-428.

Wang J., Liu X., Song Z., Shao Z. (2015a) An improved maxwell creep model for salt rock, Geomech. Eng. 9, 4, 499-511.

Wang T., Yang C., Yan X., Daemen J.J.K. (2015b) Allowable pillar width for bedded rock salt caverns gas storage, J Petrol. Sci. Eng. 127, 433-444.

Wang T., Yang C., Ma H., Li Y., Shi X., Li J., Daemen J.J.K. (2016) Safety evaluation of salt cavern gas storage close to an old cavern, Int. J. Rock Mech. Min. 83, 95-106. 
Wang T., Yang C., Li J., Li J., Shi X., Ma H. (2017) Failure analysis of overhanging blocks in the wall of a gas storage salt cavern: A case study, Rock Mech. Rock Eng. 50, 1, 125-137.

Wang T., Ma H., Shi X., Yang C., Zhang N., Li J. (2018a) Salt cavern gas storage in an ultra-deep formation in Hubei, China, Int. J. Rock Mech. Min. 102, 2, 57-70.

Wang T., Ding S., Wang H., Yang C., Shi X., Ma H., Daemen J. (2018b) Mathematic modelling of the debrining for a salt cavern gas storage, J. Nat. Gas Sci. Eng. 50, 205-214.

Wang T., Li J., Jing G., Zhang Q., Yang C., Daemen J. (2019) Determination of the maximum allowable gas pressure for an underground gas storage salt cavern - a case study of Jintan, China, J. Rock Mech. Geotech. Eng. 11, 2, 251-262.
Yang C., Li Y., Chen F. (2009) Bedded salt rock mechanics and engineering, Science Press, Beijing. (in Chinese).

Yang C., Li Y., Zhou H. (2015a) Failure mechanism and protection of salt caverns for large-scale underground energy storage, Science Press, Beijing. (in Chinese).

Yang C., Wang T., Li Y., Yang H., Li J., Xu B., Daemen J.J.K. (2015b) Feasibility analysis of using abandoned salt caverns for large-scale underground energy storage in China, Appl. Energy 137, 467-481.

Yang C., Wang T., Qu D., Ma H., Li Y., Shi X., Daemen J.J.K. (2016) Feasibility analysis of using horizontal caverns for underground gas storage: A case study of Yunying salt district, J. Nat. Gas Sci. Eng. 36, 252-266. 